\title{
Rising trend and indications of caesarean section at the university of Maiduguri teaching hospital, Nigeria
}

\author{
Ado D. Geidam, Bala M. Audu, Bello M. Kawuwa, Jessy Y. Obed \\ Department of Obstetrics and Gynaecology, University of MaiduguriTeaching Hospital Maiduguri, Borno Nigeria
}

Comespondence to: Dr Ado D. Geidam, Department of Obstetrics and Gynaecology, University of MaiduguriTeaching Hospital, P.M.B. 1414 Maiduguri, Borno State, Nigeria. E-mail: adogeidam@ yahoo.com

\begin{abstract}
Objective: To determine the trend and indications for the use of caesarean delivery in our environment. Method: A retrospective review of the caesarean sections performed at University of Maiduguri Teaching Hospital from January 2000 to December 2005 inclusive.

Results: During the study period, there were 10,097 deliveries and 1192 caesarean sections giving a caesarean section rate of $11.8 \%$. The major maternal indications were cephalopelvic disproportion (15.5\%), previous caesarean section (14.7\%), eclampsia (7.2\%), failed induction of labor (5.5\%), and placenta previa (5.1\%). Fetal distress (9.6\%), breech presentation (4.7\%), fetal macrosomia (4.3\%), and pregnancy complicated by multiple fetuses $(4.2 \%)$ were the major fetal indications. The caesarean section rate showed a steady increase over the years (7.20\% in $2000-13.95 \%$ in 2005), but yearly analysis of the demographic characteristics, type of caesarean section, and the major indications did not reveal any consistent changes to account for the rising trend except for the increasing frequency of fetal distress as an indication of caesarean section over the years, which was also not statistically significant $\left(\chi^{[2]}=8.08 ; P=0.12\right)$. The overall perinatal mortality in the study population was found to be $72.7 / 1000$ birth and despite the rising rate of caesarean section, the perinatal outcomes did not improve over the years.

Conclusion: Trial of vaginal birth after caesarean section in appropriate cases and use of cardiotocography for continuous fetal heart rate monitoring in labor with confirmation of suspected fetal distress through fetal blood acid--base study are recommended. A prospective study may reveal some of the other reasons for the increasing caesarean section rate.
\end{abstract}

Keywords: Caesarean section; demographic characteristics; indications; perinatal outcome; trend

\section{Résumé}

objectif: à déterminer la tendance et indications pour l'utilisation de la livraison caesarean dans notre environnement. méthode: Un examen rétrospectif des sections de chlorure effectuée à I'Université des Maiduguri Teaching Hospital de janvier 2000 à décembre 2005 inclus.

résultats: Pendant la période d'étude 10,097 livraisons et ont été 1192 chlorure sections donnant un taux de césarienne de $11,8 \%$. Les grandes maternelle indications ont été cephalopelvic disproportion (15,5\%), chlorure précédente section $(14,7 \%)$, éclampsie $(7,2 \%)$, a échoué à induction du travail $(5,5 \%)$ et le placenta previa $(5,1 \%)$. Détresse fœtale $(9,6 \%)$, présentation de breech (4,7\%), macrosomia foetal (4,3\%) /et de la grossesse compliquée par plusieurs fœetus $(4,2 \%)$ ont été les indications du foetus majeures. Le taux de césarienne a montré une augmentation constante au fil des ans (7.19\% en 2000 à $13.95 \%$ en 2005) mais l'analyse annuelle des caractéristiques démographiques, type de césarienne et les indications majeures n'a révélé tout cohérentes modifications apportées à tenir compte de la tendance sauf pour la fréquence accrue des détresse fœtale comme une indication de césarienne les années qui a été également pas statistiquement significatif $\left(\chi^{[2]}=p 8.08=0,12\right)$. Le mortalité périnatale globale dans la population de l'étude a été jugée 72.7 / 1000 naissance et malgré le hausse du taux de césarienne, les résultats périnatales ne pas améliorer au fil des ans. conclusion: procès de naissance vaginal après une césarienne dans les cas appropriés et l'utilisation de cardiotocography pour la continu de fréquence cardiaque fœtale surveillance du travail avec la 
confirmation de détresse fœtale suspects par étude acide-base de sang du foetus sont recommandés. UN étude prospective susceptibles de révéler certaines des raisons pour l'augmenter taux de césarienne.

Mots cles: chlorure section indications; caractéristiques démographiques; Trend; issue périnatale

DOI: 10.4103/1596-3519.56242 PMID: 19805945

\section{Page 128 Introduction}

Caesarean section is one of the commonly performed surgical procedures in obstetric and is certainly one of the oldest operations in surgery. ${ }^{[1]}$ The objective of caesarean section in the ancient world was mainly postmortem delivery of dead or alive fetus. In the early medieval period, caesarean section was performed by midwives or clergy purely in a religious context. Withdrawal of surgery from religious authority in renaissances times led to the emergence of caesarean section as a medical procedure $^{[2]}$

One of the most dramatic features of modern obstetrics is the relentless increase in the caesarean section rate. ${ }^{[3]}$ This escalating caesarean section rate is a major public health problem because caesarean section increases the health risk for mothers and babies as well as the cost of health care compared with normal deliveries. ${ }^{[4]}$ While this increase has been attributed to the fear of litigation, more liberal use of caesarean section for breech presentation, the detection of fetal distress by continuous electronic fetal monitoring, abdominal delivery of growthretarded infant, and improved safety of caesarean section in developed countries; the reasons are less clear in developing countries. ${ }^{[5,6]}$ In Nigeria, for example, in spite of the high incidence of caesarean section and increasing rate noted in many studies, there is paucity of literature with regard to the reason for such findings. ${ }^{[5,7]}$ Some of the reasons being adduced include, the specialist and referral nature of some of the hospitals, unbooked status of most of the patients, increasing use of fetal heart rate abnormalities alone as a measure of diagnosis of fetal distress in labor, overdiagnosis of cephalopelvic disproportion by junior doctors, and use of repeat caesarean section for patients with a previous caesarean section. ${ }^{[4,8,9]}$ Perinatal mortality rate shows no significant diminution despite the increasing caesarean section rate. ${ }^{[6]}$ This increasing trend of caesarean section might be stopped and even reversed without detriment to a continuing improvement in maternal and fetal health. ${ }^{[6]}$ This is particularly important in developing countries like Nigeria where large family size is a norm. Women also have great dislike for caesarean section especially when there is no living child to show for it and would often try vaginal delivery at home or religious houses after a section thus predisposing themselves to uterine rupture with its resultant morbidity and mortality. It is proposed that careful probing of the trend and indications for the use of caesarean delivery may identify pathway to lower the caesarean section rate ${ }^{[10]}$ which was informed in this study.

\section{Materials and Methods}

All caesarean sections performed at University of Maiduguri Teaching Hospital, Maiduguri from January 2000 to December 2005 inclusive were reviewed. Information was obtained from theater records, labor ward records, neonatal ward records, and retrieved patients' case notes. Data were collected on the age, parity, booking status, indications, perinatal outcome, and the type of caesarean section (emergency or elective). The indications were classified as maternal and fetal. Because of its effect on perinatal outcome, obstructed labor from all causes was separated from cephalopelvic disproportion where obstruction did not occur. All decisions to undertake each caesarean section were discussed with a consultant.

The information obtained were coded and transferred onto a profoma already design for the study. Demographic factors were reported as percentages. Yearly analysis of the caesarean section was then done. Figures were used to demonstrate the trend of the major maternal and fetal indications, while Pearson chi square and chi square test for trend were used to determine a significant association between categorical variables and significant trend, respectively. The level of significance was set at $P=<0.05$. The software SPSS version 11 (SPSS, Chicago, IL, USA) and InStat 3 (Graph Pad Software Inc., San Diego, CA, USA) were used for the analysis.

\section{Results}

During the study period, there were 10,097 deliveries and 1192 caesarean sections giving an overall caesarean section rate of $11.8 \%$. The age 
and parity distribution, booking status, and type of caesarean section are shown in Table 1 . The age of the patients ranged between 14 and 46 years with a mean age of 27.45 years. A majority of the patients $(52.8 \%)$ were between 20 and 29 years of age. Their parity ranged between 0 and 14, 36.7\% were primigravidae. Emergency caesarean section was performed in $79.4 \%$ of the cases, although $78.9 \%$ of the patients were booked patients.

Table 2 showed the indications for the caesarean sections in this study. Maternal indications constituted $76.1 \%$ and fetal indications $23.9 \%$. The leading maternal indications were cephalopelvic disproportion (15.5\%), previous caesarean section $(14.7 \%)$, eclampsia $(7.2 \%)$, failed induction of labor $(5.5 \%)$, placenta previa $(5.1 \%)$, severe pregnancyinduced hypertension $(4.8 \%)$, and obstructed labor $(4.4 \%)$. Major fetal indications include fetal

\begin{tabular}{lcc}
\hline $\begin{array}{l}\text { Table 1: Age, parity, booking status and type of } \\
\text { caesarean section }\end{array}$ & \\
\hline Age group & Frequency & Percentage \\
\hline $10-19$ & 112 & 9.4 \\
$20-29$ & 629 & 52.8 \\
$30-39$ & 423 & 35.5 \\
$40-49$ & 28 & 2.3 \\
Total & 1192 & 100 \\
Parity & & \\
0 & 438 & 36.7 \\
$1-4$ & 572 & 48.5 \\
$>5$ & 176 & 14.8 \\
$\quad$ Total & 1192 & 100 \\
Booking status & & \\
Booked & 941 & 78.9 \\
Unbooked & 251 & 21.1 \\
$\quad$ Total & 1192 & 100 \\
Type of C/S & & \\
Emergency & 947 & 79.4 \\
Elective & 245 & 20.6 \\
Total & 1192 & 100 \\
\hline
\end{tabular}

distress (9.6\%), breech presentation (4.7\%), fetal macrosomia (4.3\%), and pregnancy complicated by multiple fetuses $(4.2 \%)$.

Table 3 depicts the first part of a yearly analysis of the caesarean sections trend with emphasis on the type of the caesarean section, booking status, parity, and perinatal mortality. There was no significant trend in the type of caesarean section $(P=0.86)$, booking status $(P=0.91)$, parity $(P=0.10)$, or perinatal mortality ratios $(P=0.87)$ over the years despite the rising caesarean section rate. The overall perinatal

Page | 129

\begin{tabular}{|c|c|c|}
\hline Indications & Frequency & Percentage \\
\hline Maternal & 908 & 76.1 \\
\hline Fetal & 285 & 23.9 \\
\hline \multicolumn{3}{|l|}{ Maternal } \\
\hline $\begin{array}{l}\text { Cephalopelvic } \\
\text { disproportion }\end{array}$ & 185 & 15.5 \\
\hline $\begin{array}{l}\text { Previous caesarean } \\
\text { section }\end{array}$ & 176 & 14.7 \\
\hline Eclampsia & 86 & 7.2 \\
\hline Failed Induction & 65 & 5.4 \\
\hline Placenta previa & 61 & 5.1 \\
\hline Severe PIH & 57 & 4.8 \\
\hline Obstructed labor & 52 & 4.4 \\
\hline Others* & 125 & 10.5 \\
\hline \multicolumn{3}{|l|}{ Fetal } \\
\hline Fetal distress & 115 & 9.6 \\
\hline Breech & 56 & 4.7 \\
\hline Macrosomia & 52 & 4.3 \\
\hline $\begin{array}{l}\text { Pregnancy complicated } \\
\text { by multiple fetuses }\end{array}$ & 50 & 4.2 \\
\hline Transverse lie & 33 & 2.7 \\
\hline Postdatism & 28 & 2.3 \\
\hline Others $^{* *}$ & 51 & 4.3 \\
\hline \multicolumn{3}{|c|}{$\begin{array}{l}\text { Others }{ }^{*}=\text { abruption }(2.8 \%) \text {, failure to progress }(2.0 \%) \text {, prolong } \\
\text { infertility }(1.7 \%) \text {, bad obstetrics history }(1.2 \%) \text {, cervical dystocia } \\
(0.9 \%), \text { VVF repair }(0.7 \%) \text {, advanced maternal age }(0.7 \%) \text { and } \\
\text { uncontrolled diabetes mellitus }(0.5 \%) \text {. Others }{ }^{*}=\text { Malpositions } \\
(1.3 \%) \text {, PMTCT }(1.3 \%) \text { Cord prolapse }(1.0 \%) \text {, severe IUGR }(0.7 \%) \text {. }\end{array}$} \\
\hline
\end{tabular}

Table 3: Yearly analysis of caesarean section trend

\begin{tabular}{|c|c|c|c|c|c|c|}
\hline & 2000 & 2001 & 2002 & 2003 & 2004 & 2005 \\
\hline Deliveries & 1290 & 1400 & 1837 & 1819 & 1787 & 1964 \\
\hline Total C/S & 93 & 148 & 186 & 242 & 249 & 274 \\
\hline CSR (\%) & 7.20 & 10.57 & 10.13 & 13.30 & 13.93 & 13.95 \\
\hline Emergency & $74.2 \%$ & $82.4 \%$ & $79 \%$ & $82.2 \%$ & $82.7 \%$ & $74.4 \%$ \\
\hline Elective & $25.8 \%$ & $17.6 \%$ & $21 \%$ & $17.8 \%$ & $17.3 \%$ & $25.6 \%$ \\
\hline$\chi^{2}=0.0031$ & $P=$ & 0.86 & & & & \\
\hline Booked & $82.8 \%$ & $83.1 \%$ & $66.6 \%$ & $76.8 \%$ & $85.5 \%$ & $79.6 \%$ \\
\hline Unbooked & $17.2 \%$ & $16.9 \%$ & $33.4 \%$ & $23.2 \%$ & $14.5 \%$ & $20.4 \%$ \\
\hline$\chi^{2}=0.014$ & $P=$ & 0.906 & & & & \\
\hline Para 0 & $45 \%$ & $40.5 \%$ & $34.9 \%$ & $38.8 \%$ & $33.7 \%$ & $34.7 \%$ \\
\hline Para $\geq 1$ & $55 \%$ & $59.5 \%$ & $65.1 \%$ & $61.2 \%$ & $66.3 \%$ & $65.3 \%$ \\
\hline$\chi^{2}=2.717$ & $P=$ & 0.10 & & & & \\
\hline Peri. Death & 92 & 100 & 134 & 135 & 131 & 142 \\
\hline Total del. & 1290 & 1400 & 1837 & 1819 & 1787 & 1964 \\
\hline PMR & $71.4 / 1000$ & $72.9 / 1000$ & $74.2 / 1000$ & $73.3 / 1000$ & $72.3 / 1000$ & $71.3 / 1000$ \\
\hline$\chi^{2}=0.029$ & $P=$ & 0.86 & & & & \\
\hline
\end{tabular}


mortality of the study population was $72.7 / 1000$ birth. Despite the increasing caesarean section rate over the years, there was no improvement in the perinatal outcomes.

Figure 1 is a histogram showing the major maternal indications of the caesarean section over the years. None of these indications show any rising pattern over the years.

Figure 2 shows a histogram of the major fetal indications over the years. With the exception of fetal distress that shows a progressive increase, there was no discernable trend in the other indications to possibly account for the increasing caesarean section rate. The rising fetal distress was also found

Page $\mid 130$

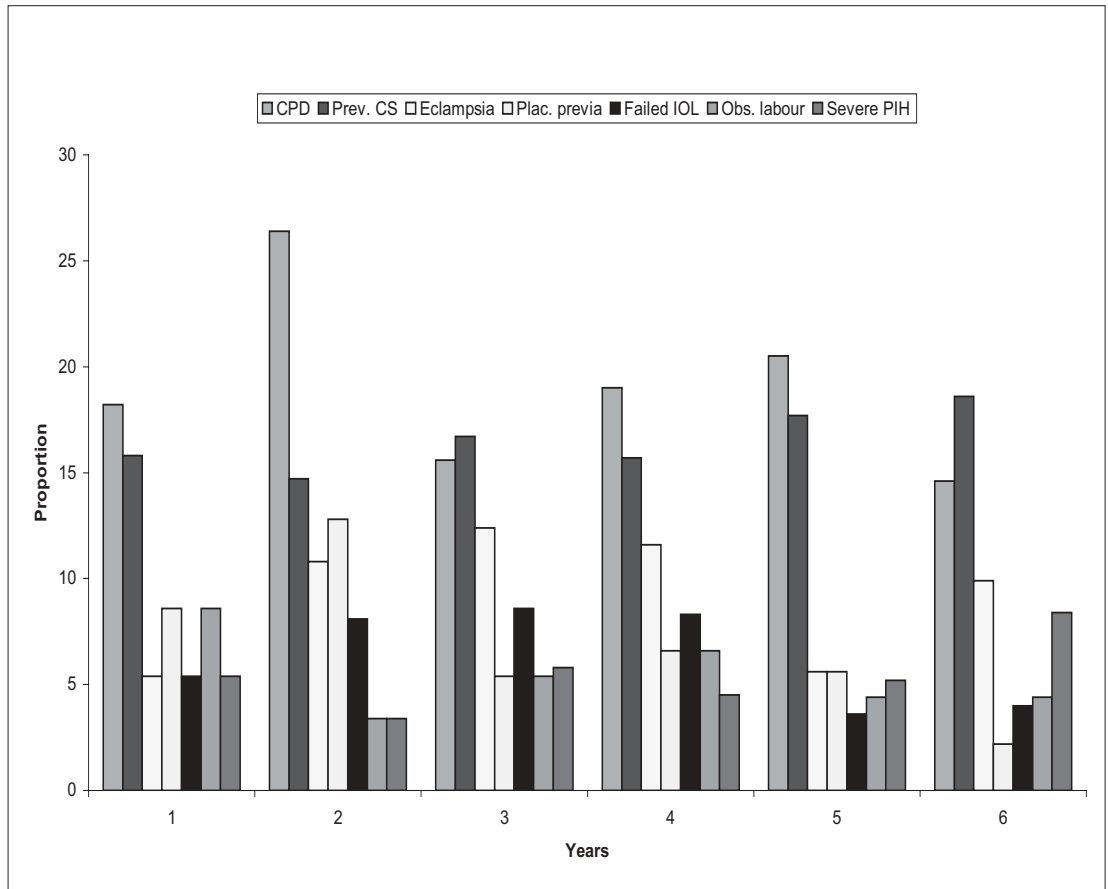

Figure 1: Trend of the major maternal indications. Year $1=2000$ Year2 $=2001$ Year3 32002 Year4 $=2003$ Year $5=2004$ Year6 $=2005$

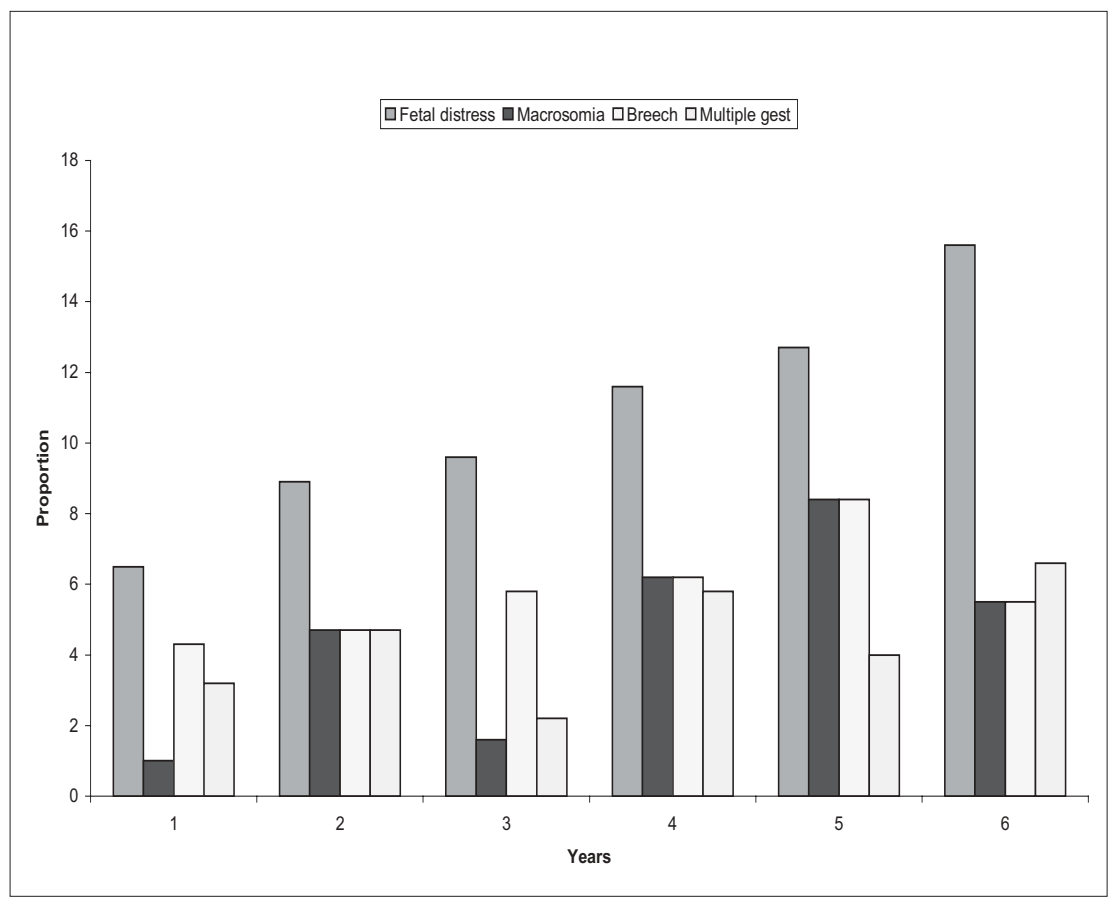

Figure 2: Trend of the major fetal indications. Year $1=2000$ Year2=2001 Year3=2002 Year4=2003 Year5 $=2004$ Year6 $=2005$ 
not statistically significant when it was subjected to trend analysis $(P=0.15)$.

\section{Discussion}

The caesarean section rate of $11.8 \%$ in this study was lower than the $18 \%$ reported from Jos northern Nigeria, ${ }^{[11]} 23.1 \%$ reported from Sagamu southern Nigeria $^{[5]}$ and $24.1 \%$ reported from Pakistan, ${ }^{[4]}$ a developing country like Nigeria. The caesarean section rate was within the $15 \%$ recommended by the World Health Organization (WHO) for developing countries. ${ }^{[12]}$

The frequency of caesarean section depends on the inherent characteristics of the obstetrics population, socio-demographic pattern, referral role of the hospital, departmental policies regarding management of cases of dystocia, breech, fetal distress and previous caesarean section, physician factor, medico-legal aspects, and consideration of maternal choice and wishes. ${ }^{[4]}$ The lower rate of caesarean section in this study might be because of the use of instrumental vaginal delivery in appropriate cases in our institution. Another possibility may be the dilution effect of the patient population, as majority of them were at low risk because our department accepted all categories of patients (both self-referred low risk and high-risk patients referred from other centers).

In this study, $52.8 \%$ of the caesarean sections were performed in patients within the age range 20-29 years which was similar to $77 \%$ reported from a study in another developing country. ${ }^{[13]}$ This might be because this age group represents the most reproductively active age group. The caesarean section rate of $36.7 \%$ in primigravidae is higher than the $25 \%$ reported from Sagamu, Nigeria. ${ }^{[5]}$ This is unacceptably high because of the implications of caesarean section on the future reproductive carrier of these groups of patients, especially in this environment large family size is desired.

Similar to an earlier study in the same hospital ${ }^{[14]}$ and studies from other parts of Nigeria, ${ }^{[5,11,15]}$ a majority of the caesarean sections in this study (79.4\%) were performed as an emergency but surprisingly $78.9 \%$ of the patients were booked. It would have been expected that the unbooked population will be higher because it is an unbooked status that was related to higher incidence of emergency caesarean section. ${ }^{[5]}$ This discrepancy may be due to the high poverty level in our environment such that only those who can afford the moderate cost patronize our hospital and those normally booked for antenatal care. Those who cannot afford have to resort to other centers where they can get cheaper services even in emergency situations. Moreover, sub-analysis of the rate of emergency caesarean sections according to booking status of the patients showed a higher rate among the unbooked patients (15.1\%) compare to the booked patients (8.5\%).

Maternal indications constituted $58.5 \%$ of the caesarean section in this review, the most common of which is cephalopelvic disproportion (18.6\%) which is similar to the reports from other parts of the country ${ }^{[11,15]}$ and other developing countries. [4,16,17] Because nutritional factors have dominant influence on pelvic size and shape and malnutrition especially during childhood result in pelvic contraction and general growth stunting; ${ }^{[18]}$ this high incidence of cephalopelvic disproportion may not be unrelated to the malnutrition that is still rampant in developing countries including Nigeria. Previous caesarean section was the second most common maternal indication (17.6\%) and is similar to the $16 \%$ reported from Ethiopia, ${ }^{[17]}$ but is higher than the $12 \%$ reported from Sagamu Nigeria. ${ }^{[5]}$ Previous caesarean section was said to constitute the highest single indication for repeat section because obstetricians still regard vaginal birth after previous caesarean section as a high-risk option. Trial of labor under close monitoring in carefully selected patient is now increasingly being advocated and it is reported that $64.8-86.0 \%$ of patients with a caesarean section who were allowed for trial of labor delivered without any complication. ${ }^{[3,19]}$ Fetal distress was the leading fetal indication and it accounted for $11.6 \%$ of all the caesarean sections performed in this study. This was higher than $6.0 \%$ reported from Ethiopia, 3.5\% reported from Pakistan but lower than $19 \%$ reported from Zaire. ${ }^{[13,16,17]}$ This high value may not be unrelated to the use of intermittent auscultation and nature of amniotic fluid as a means of fetal monitoring during labor in the study center, because there were no facilities for electronic fetal heart rate monitoring or fetal blood acid--base study. With this method, the diagnosis of fetal distress largely depends on clinical signs (fetal heart rate abnormalities, meconium staining of the liquor) which might be associated with incorrect diagnosis sometimes.

Fetal macrosomia was responsible for $5.2 \%$ of all the caesarean sections in this study. This high value may be the result of its association with other maternal indications like cephalopelvic disproportion and obstructed labor.

Although $6.7 \%$ increase in the caesarean section rate observed in this review was lower than the $11.3 \%$ reported from Sagamu, ${ }^{[5]} 10.9 \%$ reported from Ghana ${ }^{[1]}$ and $12 \%$ reported from the United Kingdom; ${ }^{[20]}$ the period of the study was 6 years 
compared to the 9 years in the Sagamu study and 20 years in the Ghana and United Kingdom reports. If allowed to continue, this rise may reach or even surpass those figures. Analysis of the parity, booking status, types of caesarean section, and the major indications of the caesarean section over the years did not reveal any significant trend that can be responsible for the increasing caesarean section rate, except for increasing trend of fetal distress as an indication. This alone cannot explained this rising caesarean section trend, more so that it was not statistically significant $(P=0.15)$. Another probable reason might be attitudinal change of the doctors, most likely because of the increasing patient load as evidenced by the increasing number of deliveries over the years. As there is no corresponding increase in the number of the doctors during the study period (29 in 2000 vs. 27 in 2005), this could have caused a low threshold to restoring to caesarean section when a problem arises during the management of a laboring patient.

For some years, doubt has been shed upon whether the observed increase in caesarean section can be justified in terms of perinatal statistics. In developed countries, there has been no significant diminution in the perinatal mortality rate despite the increase in the caesarean section rates. ${ }^{[6]}$ Although the perinatal mortality rate in this study of $72.7 / 1000$ birth is lower than reported from other studies, ${ }^{[11,16,17]}$ it did not significantly differ from the overall perinatal mortality rate of $76.3 / 1000$ birth during the study period. Despite the increasing caesarean section rate, the perinatal outcome did not improved. In fact, the rate showed a rising trend at a stage $(2000-2003)$ although it decreased after that.

\section{Conclusion}

Although the caesarean section rate of $11.8 \%$ observed in his review is within the $15 \%$ recommended by the world WHO for developing countries, ${ }^{[12]}$ the rising trend over the years is worrisome especially that the perinatal outcome is not consistently improving. If unchecked, the rate might reach unacceptable levels. Because the previous caesarean section was a major maternal indication, it is recommended that trail of vaginal birth after caesarean section should be encouraged in appropriate cases. Use of cardiotocography for continuous fetal heart rate monitoring in labor with confirmation of suspected fetal distress through fetal blood acid--base study is also recommended. There is the need for a prospective study to evaluate the reasons for the increasing caesarean section rate in our environment.

\section{References}

1. Kwawukume EY. Caesarean section. In: Kwawukume $E Y$, Emuveyan E, editors. Comprehensive obstetrics in the tropic. Asante and Hittcher Printing Press Limited, 2000. p. 321-9.

2. Lurie S, Glezerman M. The history of caesarean technique. Am J Obstet Gynaecol 2003;189:1803-6.

3. Tunar MJ. Delivery after one previous caesarean section. Am J Obstet Gynaecol 1997;176:741-4.

4. Naymi RS, Rehan N. Prevalence and determinants of caesarean section in a Teaching Hospital of Pakistan. J Obstet Gynaecol 2000;20:479-83.

5. Oladapo OT, Sotunsu JO, Sule-Odu AO. The rise in caesarean birth rate in Sagamu, Nigeria: Reflection of changes in obstetrics practice. J Obstet Gynaecol 2004:24:377-81.

6. Beazley JM. Caesarean section. In: Chamberlain G, Turnbull SA, editors. Obstetrics. $1^{\text {st }}$ ed. Churchill Livingstone Publication; 1993. p. 857-65.

7. Njokanma FO, Egri-Okwargi MT, Nwokoro CA, Orebamjo T, Okeke GC. Birth asphyxia, perinatal and maternal mortality associated with caesarean section. Trop J Obstet Gynaecol 2002;19:25-9.

8. Iloabachie GC, Meniru GI. Trends in caesarean section. Niger J Surg Sci 1992;2:75-81.

9. Adeleye JA. Caesarean section for clinically diagnosed fetal distress: An unjustified assault. Trop J Obstet Gynaecol 1987;6:37-8.

10. Notzon FC, Cnattingius S, Bergijo P, Cole S, Taffel S, Irgens L, et al. Caesarean section delivery in the 1980s; International comparison by indication. Am J Obstet Gynaecol 1994;170:495-504.

11. Aisien AO, Lawson JO, Adebayo AA. A five year appraisal of caesarean section in a Northern Nigeria University Teaching Hospital. Niger Postgrad Med J 2002;9:146-50.

12. World Health Organization. Appropriate technology for birth. Lancet 1985:2:436-7.

13. Dey N, Hatai SK. A study of caesarean section cases with special reference to maternal and neonatal outcome. J Indian Med Assoc 1992;90:149-51.

14. Chama CM, El-Nafaty AU, Idrisa A. Caesarean morbidity and mortality at Maiduguri, Nigeria. J Obstet Gynaecol 2000;20:45-8.

15. Onwudiegwu U, Ezechi OC. Emergency obstetrics admissions: Late referrals, misdiagnosis and consequences. J Obstet Gynaecol 2001;21:570-5.

16. Onsrud L, Onsrud M. Increasing caesarean section, even in developing countries. Tidsskr Nor Laegeforen 1996;116:67-71.

17. Ali Y. Analysis of caesarean delivery in Jimma Hospital, south-western Ethiopia. East Afr Med J 1995;72:60-3.

18. Myerscough P. Cephalopelvic disproportion. In: Chamberlain G, Turnbull SA, editors. Obstetrics. $1^{\text {st }}$ ed. Churchill Livingstone Publication; 1993. p. 813-21.

19. Ilesanmi AO, Odukogbe A, Olaleye DO. Vaginal delivery after one caesarean section in Nigerian women. J Obstet Gynaecol 1997;17:139-42.

20. Sanders J, Beatie B, Chaundhry S. Caesarean section. Royal College of Obstetricians and Gynaecologist guideline, 2004. p. 1-165.

Source of Support: Nil, Conflict of Interest: None declared. 